\title{
PARAFFIN AND COLLODION EMBEDDING.
}

H. N. Conser, Sunbury, Pa.

Paraffin and collodion, in their modifications, answer now so nearly every requirement of embedding media, that, excepting the rarest cases, there is no further need of the soap, gum and gelatine mixtures.

For a large class of tissues either paraffin or collodion may be used. Here, then, is the province of choice in methods, but aside from this the question is not one of respective merits, but rather a consideration of the method indicated for the work at hand.

Some years' experience with a wide variety of material by both methods has led to the observations of this paper. The choice of a clearing agent in the paraffin method is important. Not all solvents of paraffin which are miscible with alcohol are suitable for the purpose. An extended trial of turpentine proves it of all, the most hurtful to delicate structures. The shrinkage is so much by its use that its excellent penetrating qualities are not enough to recommend it. Chloroform penetrates slowly and does very well for small pieces only. It must be gotten rid of entirely in the bath, for any quantity left in the object will render it soft and unfit for cutting. Toluol (Toluene) has in my experience given the best results. For embryos stained in toto I have never found any other clearing agent so reliable and satisfactory.

Of the paraffin itself the medium soft melting at $48-50^{\circ} \mathrm{C}$ is best for most purposes, the harder is suitable for the harder tissues, provided the higher temperature of the bath is not objectionable. Sections can be cut thinner from hard than from soft paraffin, yet, for many objects, it is better to use a soft paraffin and cut at a correspondingly lower temperature.

Tender vegetable structures if fixed from the fresh state in the chrome salts or chromic acid usually bear the dehydration and heating very well.

For embryos and the like of which sections contain separated 
parts, staining in toto and embedding in paraffin is of all methods far the most practical; the sections are easily affixed to the slide with the albumen or collodion fixatives so that loss or displacement of parts seldom occurs. Cut paraffin sections are not easily kept unless affixed to the slips, but the blocks may be kept for years if the embedding has been carefully done with good paraffin. I have found that most of the specimens that harden too much for cutting after several years' keeping to be those cleared in chloroform or those heated too long in the paraffin bath.

For the collodion method the use of Schering's celloidin is most advised. The first steps are essentially alike in the various modifications of the method and the only trouble likely to occur is from giving the collodion solutions insufficient time for perfect homogeneous penetration. Two to four days in each is enough for average objects, but any longer time can do no harm. I have had objects remain in collodion solutions two years without their having been in any wise injured. Embedding on cork or wood in a box of paper of which the cork or wood block forms the bottom is the common procedure. If the object be firm enough to bear its own weight, it may as well be embedded on the cork or wood without the surrounding paper, and placed direct in the hardening fluid, only a thin stratum of collodion surrounds the object and the formation of bubbles is obviated. In the matter of hardening there is diversity of usage. Chloroform, which must be anhydrous, gives excellent results both as to transparency and consistency of the mass, but its rapidity of action on the exterior, while the interior of the mass is slowly affected, renders it less serviceable than alcohol which hardens uniformly, and after one or several days' action yields an excellent cutting consistency. For this purpose 80 to 85 per cent. alcohol is best. Objects embedded on cork or wood may be kept in a jar with 70-80 per cent. alcohol, but discolor and deteriorate after prolonged keeping. It is better to section as soon as the mass is well hardened and keep the sections in vials of 80 per cent. alcohol until wanted. Sections preserved in this 
way for six years are yet good. Since it is often desirable to keep valuable material for future use, this feature of the collodion method is a strong one in its favor.

The dehydration of sections for mounting will depend upon whether the collodion is to be removed or retained. In the first case absolute alcohol followed by oil of cloves is good, usually it is better to retain the collodion, and then, of course, none of its solvents can be employed. Ninety-five per cent. alcohol followed by oil of bergamont, oil of origanum (the cretici) or oil of cedar wood answer the purpose well. As to the respective uses of the two methods it may be said that for serial sections and normal tissues stained in toto, the paraffin method is by far the better ; it is the one especially suited for embryology and histology.

Paraffin is not so well adapted for tissues of the central nervous system, parts of the eye, cartilaginous structures, organs containing exudations or foreign elements, nor for those objects injured by heat; for these then collodion is preferred and almost exclusively used by pathologists, being the better by reason of the above-named advantages together with the readiness with which its sections are double stained.

While the histologist and embryologist can get along with paraffin, and the pathologist with collodion alone, the best results can be obtained by the use of both, each chosen for the work it is best fitted to accomplish. 


\section{$2 \mathrm{BHL}$ Biodiversity Heritage Library}

Conser, H N. 1896. "Paraffin and Collodion Embedding." Transactions 17, 312-314.

View This Item Online: https://www.biodiversitylibrary.org/item/86837

Permalink: https://www.biodiversitylibrary.org/partpdf/90833

\section{Holding Institution}

University of Toronto - Gerstein Science Information Centre

\section{Sponsored by}

University of Toronto

\section{Copyright \& Reuse}

Copyright Status: Not provided. Contact Holding Institution to verify copyright status.

This document was created from content at the Biodiversity Heritage Library, the world's largest open access digital library for biodiversity literature and archives. Visit BHL at https://www.biodiversitylibrary.org. 